\title{
Contrastive analysis of compliments given by Facebook commentators in the pages of Iranian and England foreign ministers
}

\author{
Masoumzadeh, Ali $\measuredangle$ \\ Kashan University, Iran (Ali.masoumzadeh64@gmail.com) \\ Ghanadi, Seyed Ali \\ Kashan University, Iran (Ali.ghanad@yahoo.com)
}

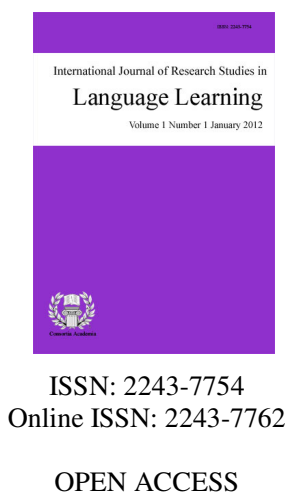

Received: 22 May 2015

Revised: 14 July 2015 DOI: $10.5861 /$ ijrsll.2015.1243

Accepted: 12 September 2015

\section{Abstract}

This study aims at conducting a contrastive analysis of the most frequent compliment strategies used in Iranian and British foreign minister Facebook pages. It also investigated the impact of cultural and social norms on the choice of compliment strategies in the utterances of the commentators. The data were collected through surfing the pages of both Iranian and British foreign ministers (150 tokens for each of them). Then, by using Yuan' (2002) classification of compliment strategies, the comments were analyzed in terms of two major categories namely bound and unbound semantic formulas. Furthermore, the most frequently used compliment strategy by Facebookers on the wall of British foreign minister is explicit semantic formula while implicit patterns were highly used by commentators in Iranian foreign minister's page. As a result, the remarkable frequency differences of these two categories reflect the influence of cultural standards on selecting various compliment strategies.

Keywords: contrastive analysis; compliment; compliment strategies; Facebooker; foreign minister; semantic formula 


\section{Contrastive analysis of compliments given by Facebook commentators in the pages of Iranian and England foreign ministers}

\section{Introduction}

By considering language and function, speech act theory is mainly concerned with the different acts performed by means of utterances in a communication act consisting of locutionary, illocutionary, and perlocutionary acts. Locutionary acts are defined as the speech acts that have occurred, illocutionary acts are those real actions done by an utterance i.e. saying is equivalent to doing, like welcoming and warning, and perlocutionary acts are the consequences of the utterance on the listener, who, e.g. accepts the bet or pledge of marriage.

Searle (2003) classified illocutionary acts into five categories as follows:

$>$ Representatives: a speech act which describes states or events in the world, such as an assertion, a claim, a report and etc.

Directives: a speech act that has the function of getting the listener to do something, such as a suggestion, a request and etc.

$>$ Commissives: a speech act that commits the speaker to doing something in the future, such as a promise or a threat

$>$ Declaratives: a speech act which changes the state of affairs in the world.

Dxpressives: a speech act in which the speaker expresses feelings and attitudes about something, such as an apology, a complaint and : compliments"

Facebook has been a dominant presence in our lives in recent years. The debate about Facebook has only just begun in academic context as a subject of much discussion and exchange of arguments. Furthermore, there are many things about Facebook use and users that need to be understood before we embrace it as a tool that can be utilized for activities other than leisure and social interaction in a digital space. Compliments are also common on online social networks like Facebook and Twitter. Since the focus of most studies conducted so far have been on face-to-face compliments and neglected relatively new communicative contexts such as social networks, this study examines and evaluates different compliments that users leave on the walls.

\section{Literature Review}

Many studies have focused on the differences in the use of pragmatic strategies, particularly compliments and compliment responses as "mirrors of cultural values" (Manes, 1983). Regarding the structural dimensions of compliments, Wolfson and Manes (1980) were pioneers in examining the formulaic patterns of complimenting in the levels of syntactic and semantic. Afterwards, Janet Holmes $(1986,1988)$ exerted the functions of compliments as a framework by employing Brown and Levinson's (1987) Politeness Theory.

General appraisal of both compliments and compliment responses has taken into account by a large number of researches concerning compliment behaviors. Herbert (1997) stated that "compliment events provide interesting information on socio-cultural values and organization" (1997, p. 497). To put it simply, complimenting indicates that the participants' linguistic choices and their socio-cultural norms are inextricably intertwined. The increasing progress of social networks such as Twitter and Facebook has brought an extremely novel community in which virtually new unique pragmatic regulations have been founding (Cox, 2005). Furthermore, these new social networks such as Facebook or twitter are places for users to represent themselves 
in written form not only communicatively but also unstressedly. As a matter of fact, one of their outstanding characteristics is their hybridity in the sense that social networks amalgamate properties of spoken communication in the form of writing.

Orihuela (2008) defines social networks as:

“... web-based services that allow users to interact, share information, coordinate actions and, in general, keep in touch. These applications are the new way in which our social network is represented, but also the place where our online identity is constructed and the means by which our activity on the Net is created and shared."(Orihuela, 2008, p. 58)

Facebook users try to represent themselves in different ways in Facebook and this issue is considered by many scholars. (Bouvier, 2012; DeAndrea et al., 2010; DeWall et al., 2011). Carr et al. (2012) revealed that the utilization of speech acts in the status section of individuals' Facebook page operates as a device for self-expression and public display. This study scrutinizes the pragma-linguistic differences of English and Persian languages in evaluating others in an online context. We utilized quantitative and qualitative methods to examine, both pragmatically and semantically, compliments posted by Facebook users on the walls of Iranian and England foreign ministers. This study aims at providing answers to the following questions:

$>$ What are the most frequent compliments strategies used in Iranian and British foreign minister Facebook pages?

$>$ Do cultural and social values influence the choice of compliment strategies in the utterances of Facebooker?

\section{Method}

\subsection{Participants}

The data collection for William Hague covered the period of time between 2012 and 2013 but data gathered for Mohammad Javad Zarif was from October 2013 to December 2013.The number of compliments gathered from their pages is nearly 100 for each of them. As variables such as age, social position and educational status are not accessible for us in Facebook, they are not taken into account.

\subsection{Sampling process}

The common methods for investigating compliments are: a) discourse completion tasks (DCT); b) recall protocols; c) role plays; d) field observation; and e) writing down of a natural talk-in-interaction event. This is particularly useful if one wants to study speech acts such as apologies, invitations, refusals, and so forth. DCTs are implemented most frequently in writing, with the participants being given a description of a situation in which the speech act occurs. After the description, there is usually blank space where the response is required. The responses represent what a learner believes he or she would say in a particular context. This may or may not correspond to what would actually be said. Thus, results such as these need to be interpreted cautiously or at least verified against real situations whenever possible (Mackey, 2005). Along with DCTs, role plays simulate ideal, albeit not real, situations. Conversely, by means of field observation, the analysts collect real data.

In the present study, a corpus of 300 Facebook compliments from two foreign ministers' pages was attained. In fact, compliments were not extracted by asking Facebook users to employ compliments in their pages and postings but we analyzed actual compliments posted in the Facebook pages without any stimulus. In addition, this study takes into consideration the ethical issues and respects the privacy of examined Facebook users by not disclosing any personal details. As Paccagnella (1997) pointed out: "messages posted on semi private arenas like Facebook, where participants understand their comments will be seen by a relatively uncontrolled number of 
Masoumzadeh, A., \& Ghanadi, S. A.

people, are not private but belong to the public domain and can be used without restriction." Although ethical issues are not apparently considered in this stance in the sense that the data were collected without participants' permission a priori, we decided to announce our final research findings on the walls of the two foreign ministers in the form a post. Each of the comments in the corpus was coded and analyzed by the present researchers using the model presented in the data analysis section. For the reason that our focus on this subject is to adopt a social orientation, comments selected and analyzed provide us with a context in which social and cultural norms are interpreted.

\section{Data Analysis}

According to Yuan (2002), compliments in terms of semantics can be divided into 2 categories namely unbound semantic formula and bound semantic formula. Unbound semantic formulas refer to those expressions that can function independently as compliments, while bound semantic formulas refer to those responses that cannot be considered as compliments by themselves but must be attached to or co-occur with one of the unbound semantic formulas to be interpreted as part of a compliment. For example, in the context of Christmas message from foreign secretary William Hague:

"I thank all those who represent our nation overseas, respond to crises and travel to all corners of the world in support of Britain's economic recovery, and all those who work for a safer, fairer and more prosperous world. I wish you and your families wherever you are a Merry Christmas and a peaceful and Happy New Year."

A comment from one Facebooker is "You are a great man Mr. William, free media is destroying in Azerbaijan. Please, do not begrudge your support". This comment was not considered as valid compliment because "free media is destroying in Azerbaijan. Please, do not begrudge your support" is more of a request seeking for a support than a compliment. It must co-occur with a bound semantic formula that is "You are a great man $\mathrm{Mr}$. William" to be interpreted as part of a compliment.

Unbound semantic formulas can be further divided into two sub-types: explicit compliments and implicit compliments. Explicit compliments refer to compliments outside of context, being realized by a small set of conventional formulae (Herbert, 1997). In the current study, explicit compliments were defined as those responses that carry at least one positive semantic value. Implicit compliments are those in which the value judgment is presupposed and/or implicated by Gricean maxims (Herbert, 1997). Therefore, the positive value of an expression can be inferred from what is said in a particular situation. Bound semantic formulas include explanation, future reference, contrast, advice and request. Each type of compliment strategy is illustrated below with examples from the data, wherein $\mathrm{C}$ stands for complimenter:

\section{Unbound Semantic Formulas:}

\section{1-1 Explicit Compliment}

\section{C: A tremendous effort}

C: Excellent company, Mr. Hague!

C: doctor zarif besyar doost dashtani va ghabele ehteram hasti (Dr.Zarif you are so lovely and respectable)

In the above examples, "tremendous" and "doost dashtani" were coded as explicit compliment because they carry a positive value.

\section{1-2 Implicit Compliment}

C: Good luck Mr. Hague! It would be lovely to be a part your team one day. 
C: Kheyli azizi doctormoafagh bashed (You are so lovely, Good luck to you)

The underlined parts were coded as implicit compliment because the utterance implies that the comentator likes the complimentee's character.

\section{Bound Semantic Formulas:}

\section{2-1 Explanation:}

C: Honourable sir your contribution towards peace process especially in Asia as well as in all over the world is great.

C: Dastetan dard nakone Dr.Zarif be khatere talashhaye bivaghfe shoma dar siasat khareji. (Thanks Dr. Zariffor your endless efforts in foreign affairs)

The underlined part alone cannot be regarded as compliment. But it co-occurs with an explicit semantic formula. The function of the underlined part is to explain why the complimenter would make compliments.

\section{2-2 Future reference}

C: Nice to see you doing the right thing for a change Mr.Hague.

C: Dr. Zarif omidvaram dar 5+1 ravande mozakerat be nafe ma ragham bokhorad (Dr.Zarif I hope in 5+1 negotiation procedure will be in favor of Iranian people)

Here the complimenter refers to complimentee's bright future because of his capabilities.

\section{2-3 Contrast}

C: Thanks Mr. Hague and your efforts in rebuilding Congo DR-thanks to all British Business and Investors who's believing in Congo DR market and giving Congo a chance to boom for business.

C: Khaste nabashi doctor jan, ghatan name shoma dar kenar mosadesh va amirkabir dar hafezeye tarikhe iran sabt mishavad. (Thanks Dr. Zarif, Definitely your name will be remained beside the name of Amirkabir and Mosadegh in our history)

Here the complimenter seems to generalize the generosity to the nation of complimentee. The second sentence indicates a comparison or contrast.

\section{2-4 Advice}

C: Well done!!! Keep going, Mr. Hague.

C: faghat sadegh bash hamin be khoda zarrar nemikoni (Just be honest, Be sure that it doesn't harm you)

Besides giving a compliment, the complimenter also gives advice to the complimentee to continue his good 
Masoumzadeh, A., \& Ghanadi, S. A.

works.

\section{2-5 Request}

C: Great man! William, there was a judicial murder in Bangladesh, please speak on the matter. thank you.

C: Doctor kar balad lotfan be vaziyate zendanian siasiye residegi konid (Skillful Dr. Zarif please consider the condition of political prisoners)

In the above contexts, the complimenter is making some requests to the complimentee.

\section{Results}

The results of the analysis of the compliment data collected from Facebookers are presented in Table 1 and 2. They indicate the percentages of the subjects ${ }^{e e}$ choice of each subcategory of compliments. Each frequency and percentage represents the number of choices made out of the total number.

\section{Table 1}

Different compliment strategies used by Facebookers on the wall of British foreign minister

\begin{tabular}{|c|c|c|}
\hline Compliment strategy & Tokens & Percentage \\
\hline Explicit & 60 & 40.00 \\
\hline Implicit & 32 & 21.33 \\
\hline Explanation & 18 & 12.00 \\
\hline Future reference & 5 & 3.33 \\
\hline Contrast & 2 & 1.33 \\
\hline Advice & 13 & 8.66 \\
\hline Request & 20 & 13.33 \\
\hline Total & 150 & 100 \\
\hline
\end{tabular}

Table 2

Different compliment strategies used by Facebookers on the wall of Iranian foreign minister

\begin{tabular}{|c|c|c|}
\hline Compliment strategy & Tokens & Percentage \\
\hline Explicit & 19 & 12.66 \\
\hline Implicit & 81 & 54.00 \\
\hline Explanation & 14 & 9.33 \\
\hline Future reference & 7 & 4.66 \\
\hline Contrast & 7 & 4.66 \\
\hline Advice & 12 & 8.00 \\
\hline Request & 10 & 6.66 \\
\hline Total & 150 & 100 \\
\hline
\end{tabular}
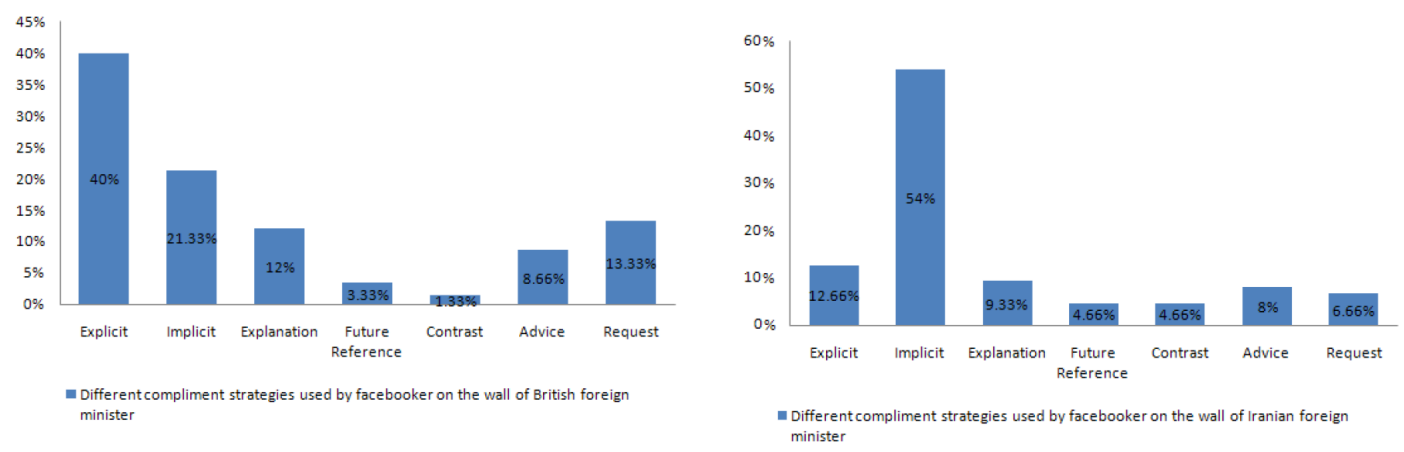
As shown in Tables 1 and 2 the most frequently used compliment strategy by Facebookers on the wall of British foreign minister is explicit semantic formula. It accounts for $40 \%$ of the 150 compliment tokens we elicited through field observation. Such findings corroborate Yuan's (2002) observation that people tend to make direct and positive statements when they pay compliments. In contrast, on the wall of Iranian foreign minister, explicit tokens fall on the second position according to compliment frequencies. As far as implicit compliments are concerned, complimenters of William Hague tend to utilize this strategy less than Facebooker comments in Zarif's page. In other words, while 54 percent of our Iranian participants make use of implicit strategy in their comments, it is seen that nearly 22 percent of Hague commentators employ it in their utterances.

In these raw data in two tables, explanation and advice compliment frequencies are not only approximately identical but noticeable and near 10 percent. Furthermore, two other compliment strategies namely future reference and contrast amount to almost under 5 percent which is negligible. In terms of request, remarkable differences between two sets of data are found i.e. the percentage of this subcategory is 13.33 and 6.66 in British and Iranian foreign ministers pages, respectively.

\section{Discussions and conclusions}

In Iranian foreign minister's page Implicit compliment category contained in most tokens the expression of gratitude and wishing success. Therefore, according to the high frequency of "implicit" among the Zarif's complimenters, it can be concluded that that they were not able to distinguish the speech act of gratitude from that of compliment giving. Thus, the nature and the felicity conditions of compliments should be explicitly instructed and the difference between compliments and gratitude should be explained.

As it was stated in advance our method cannot provide any results on the basis of demographics of the commentators such as their age, gender and social status. Simply put, personal information of Facebookers are not accessible because of Facebook policy in preserving their users' privacy. As a result, If we are to gain a full picture of complimenting speech events in social networks, other data collection should be used. It is accepted by many scholars that language is the carrier and mirror of its respective culture, and the difference in languages and in linguistic performances can also reflect the differences in communication norms, in social cultures and value preference. People, brought up in certain society and culture, become accustomed to their own interaction norms, apply the norms in their communication and judge others' speech and text by their own norms (Yu, Fu, \& Hou, 2007). Since in our study there are more explicit patterns in the British page in comparison with the Iranian page, it is implied that complimenters commented on the British foreign minister's page are more direct, expressive and straightforward than Iranian ones. Table 1 and 2 reveal that the forms adopted in comments by commentators in the British page, to a great extent, resemble the Iranian counterpart statistically in explanation, future reference, contrast, and advice semantic formulae.

\section{References}

Bouvier, G. (2012). How Facebook users select identity categories for self-presentation. Journal of Multicultural Discourses, 7(1), 37-57. http://dx.doi.org/10.1080/17447143.2011.652781

Brown, P., \& Levinson, S. (1987). Politeness: Some universals in language usage. Cambridge: Cambridge University Press.

Carmen, M.-A., \& García-Gómez, A. (2013). 'You look terrific!' Social evaluation and relationships in online compliments. SAGE, Discourse Studies, 15(6), 735-760. http://dx.doi.org/10.1177/1461445613490011

Carr, C. T., Schrock D. B., \& Dauterman, P. (2012). Speech acts within Facebook status messages. Journal of Language and Social Psychology, 31(2), 176-196. http://dx.doi.org/10.1177/0261927X12438535

Crystal, D. (2001). Language and the Internet. Cambridge: Cambridge University Press. http://dx.doi.org/10.1017/CBO9781139164771

DeAndrea, D. C., Shaw, A. S., \& Levine, T. R. (2010). Online language: The role of culture in self-expression and self-construal on Facebook. Journal of Language and Social Psychology, 29(4), 425-442. 
Masoumzadeh, A., \& Ghanadi, S. A.

http://dx.doi.org/10.1177/0261927X10377989

DeWall, C. N., Buffardi, L. E., Bonser, I., \& Campbell, W. K. (2011). Narcissism and implicit attention seeking: Evidence from linguistic analyses of social networking and online presentation. Personality and Individual Differences, 51(1), 57-62. http://dx.doi.org/10.1016/j.paid.2011.03.011

Golato, A. (2002). German compliment responses. Journal of Pragmatics, 34, 547-571. http://dx.doi.org/10.1016/S0378-2166(01)00040-6

Herbert, R. K. (1997). The sociology of compliment work in Polish and English. In N. Coupland \& A. Jaworski (Eds.), Sociolinguistics (pp. 487-500). London: Macmillan.

Holmes, J. (1988). Paying compliments: A sex preferential positive politeness strategy. Journal of Pragmatics, 12 (3), 445-465. http://dx.doi.org/10.1016/0378-2166(88)90005-7

Knapp, M. L., Hopper, R., \& Bell, R. A. (1984). Compliments: A descriptive taxonomy. Journal of Communication, 34(4), 12-32. http://dx.doi.org/10.1111/j.1460-2466.1984.tb02185.x

Lorenzo-Dus, N. (2001). Compliment responses among British and Spanish university students: A contrastive study. Journal of Pragmatics, 33, 107-127. http://dx.doi.org/10.1016/S0378-2166(99)00127-7

Machiko, A. (2003). Learning to request in a second language: A study of child inter-language pragmatics. UK: Multilingual Matters.

Manes, J. (1983). Compliments: A mirror of cultural values. In N. Wolfson \& E. Judd (Eds.), Sociolinguistics and language acquisition (pp. 96-102). Rowley, MA: Newbury House.

Manes, J., \& Wolfson, N. (1980). The compliment formula. In F. Coulmas (Ed.), Conversational routine (pp. 115-132). The Hague: Mouton.

Orihuela, J. L. (2008). Internet: la hora de las redes sociales. Nueva Revista, 119, 57-62.

Paccagnella, L. (1997). Getting the seats of your pants dirty: Strategies for ethnographic research on virtual communities. Journal of Computer-mediated Communication, 3(1). http://dx.doi.org/10.1111/j.1083-6101.1997.tb00065.x

Pomerantz, A. (1978). Compliment responses. Notes on the co-operation of multiple constraints. In J. Schenkein (Ed.), Studies in the organization of conversational interaction (pp. 79-112). London: Academic Press.

Saito, H., \& Beeken, M. (1997). An approach to instruction of pragmatic aspects: Implications of pragmatic transfer by American learners of Japanese. Modern Language Journal, 81(3), 363-377. http://dx.doi.org/10.1111/j.1540-4781.1997.tb05497.x

Searle, J. (1968). Austin on locutionary and illocutionary acts. The Philosophical Review, 77, 405-424. http://dx.doi.org/10.2307/2183008

Yuan, Y. (2002). Compliments and compliment responses in Kunming Chinese. Pragmatics, 12(2), 183-226. http://dx.doi.org/10.1075/prag.12.2.04yua 